\title{
Medullary Thyroid Carcinoma in Multiple Endocrine Neoplasia 2A A Therapeutic Challenge
}

Cardoso L1, Rodrigues $D^{1,2}$, Costa $G^{2,3}$, Moreno $C^{1}$, Guelho $D^{1}$, Vicente $\mathbf{N}^{1}$, Balsa $M^{4}$, Martins $D^{1}$, Oliveira $D^{1}$, Carrilho F1

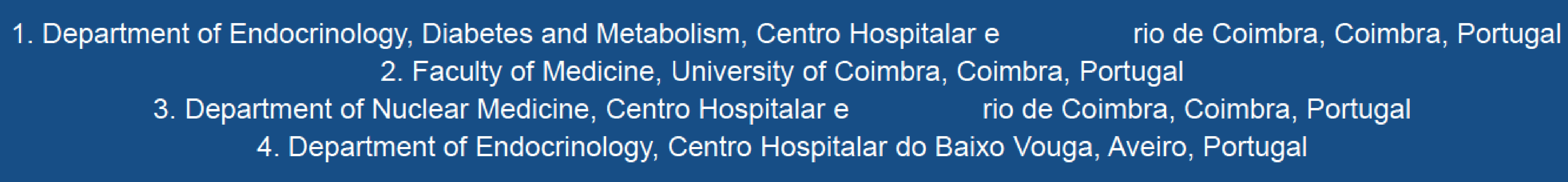

\section{Introduction}

Medullary thyroid carcinoma (MTC) occurs in a hereditary pattern in $25 \%$ of cases and accounts for approximately $4 \%$ of thyroid cancers. Virtually all patients with multiple endocrine neoplasia 2A (MEN2A) develop MTC. MTC aggressiveness and natural history varies according to the RET mutation. Prophylactic thyroidectomy may cure and/or prevent metastatic disease in most cases, which is of paramount importance due to typical chemo and radiorresistance.

\section{Case Report}

A 27-years-old man with past history of colostomy at five months of age for Hirschsprung disease and total thyroidectomy at age of 14 years old for the genetic diagnosis of MEN2A (C620R RET). Patient's underwent genetic study when his mother was diagnosed with MTC and a germline mutation in RET gene (C620R) was identified. Patient's post-operative histological diagnosis revealed two MTC foci of $1 \mathrm{~cm}$ and $0.3 \mathrm{~cm}$. Patient was lost to follow-up at the age of 16 . In the last year he reported low back pain radiated to right thigh.

\section{Initial Evaluation}

\section{Low back pain}

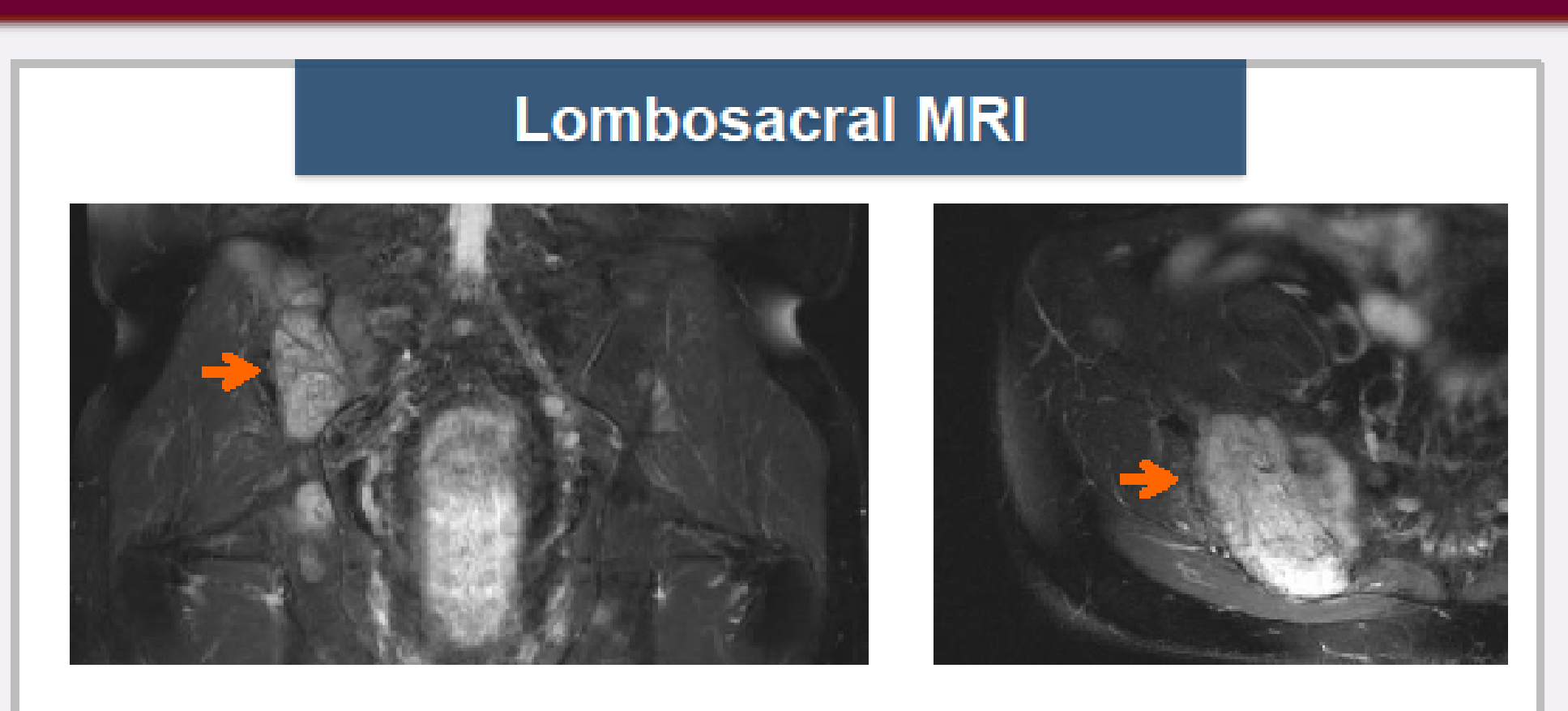

Iliac bone biopsy: lesion compatible with MTC
Examination of thyroid region

Detected two nodules in the left flank of the neck with $3 \mathrm{~cm}$ and 2 $\mathrm{cm}$ of diameter, hard consistency and absent mobility.
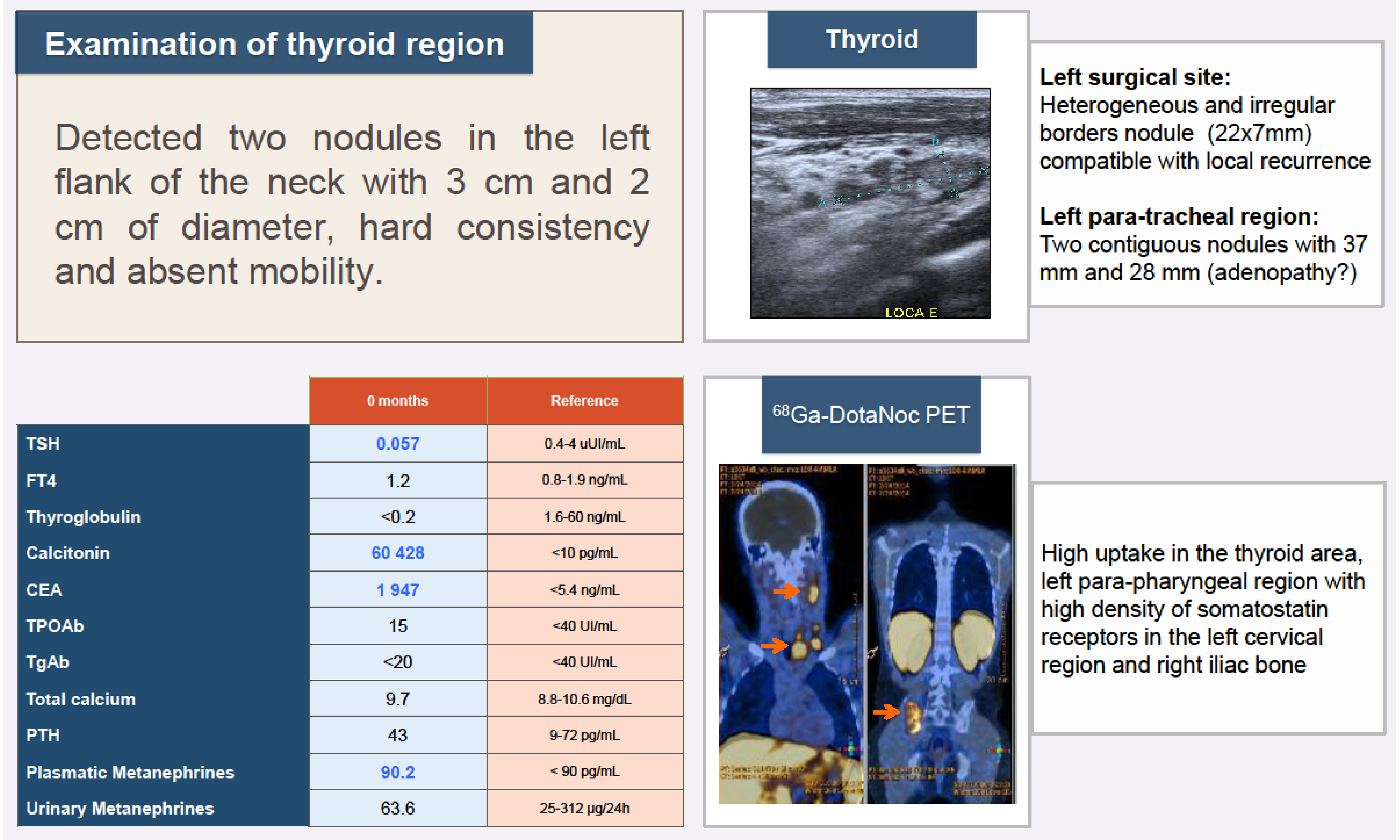

High uptake in the thyroid area, left para-pharyngeal region with
high hensity of somatostat high density of somatostall
receptors in the left cervica region and right iliac bone

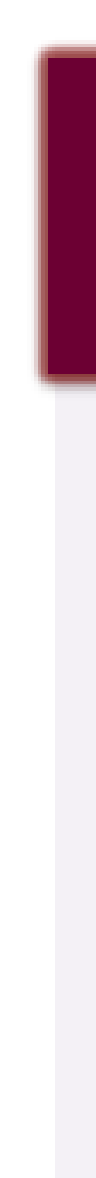

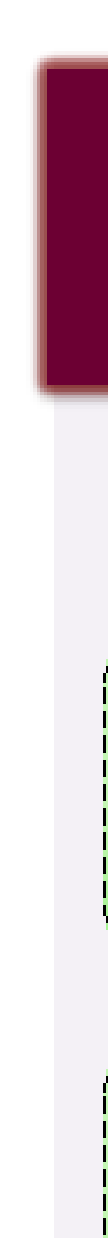

\section{Surgery}

Bilateral cervical lymph node dissection

Subtotal resection of iliac metastasis

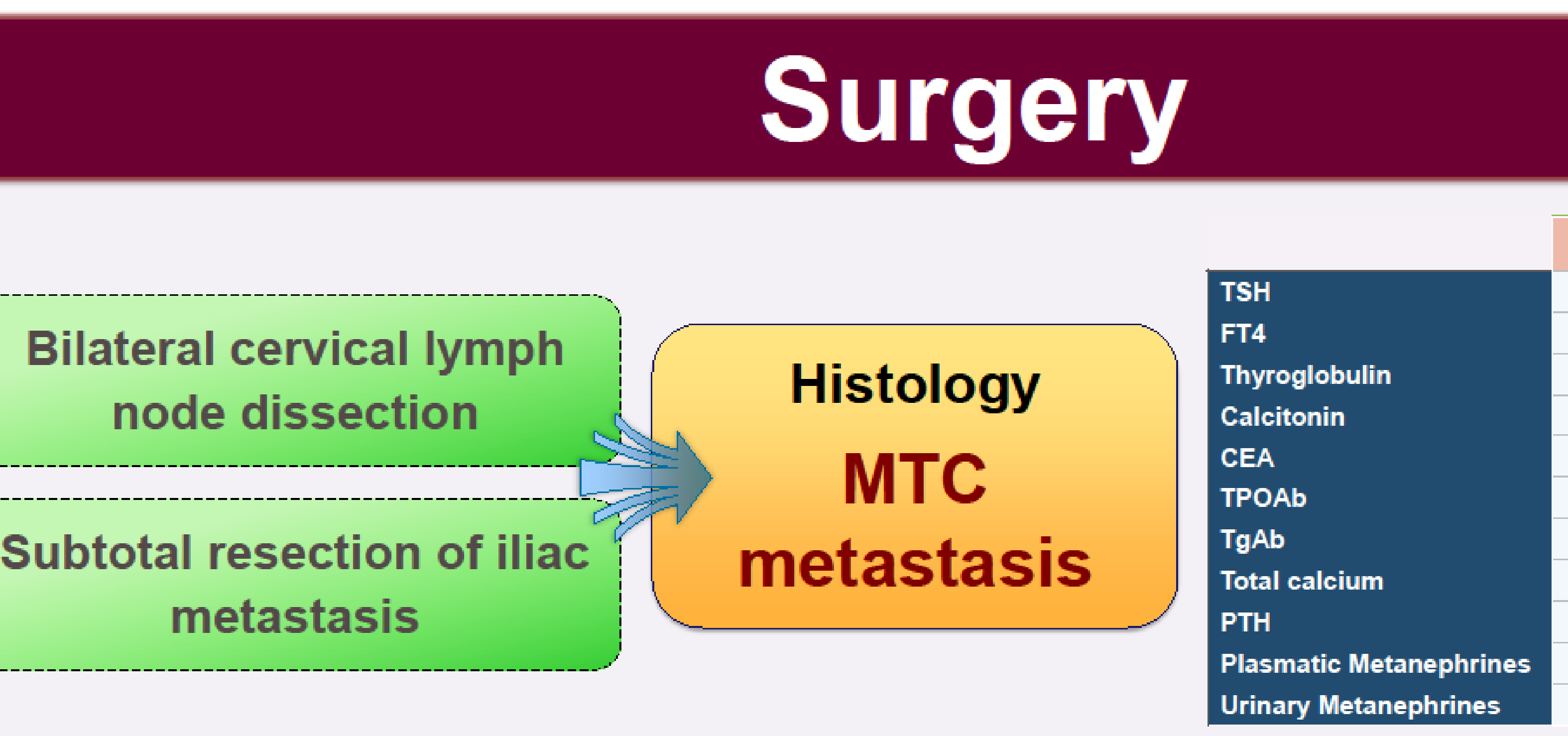

\section{Conclusion}

- $\mathrm{CMT}$ is the first manifestation of MEN2A. As shown in this case the age of prophylactic thyroidectomy is of decisive importance to the prognosis.

- Tumour somatostatin receptors heterogeneity may be responsible for different responses to radionuclides. The treatment of metastatic disease is challenging due to the poor response to systemic therapy and/or radiotherapy.

\section{Therapeutic Approach}

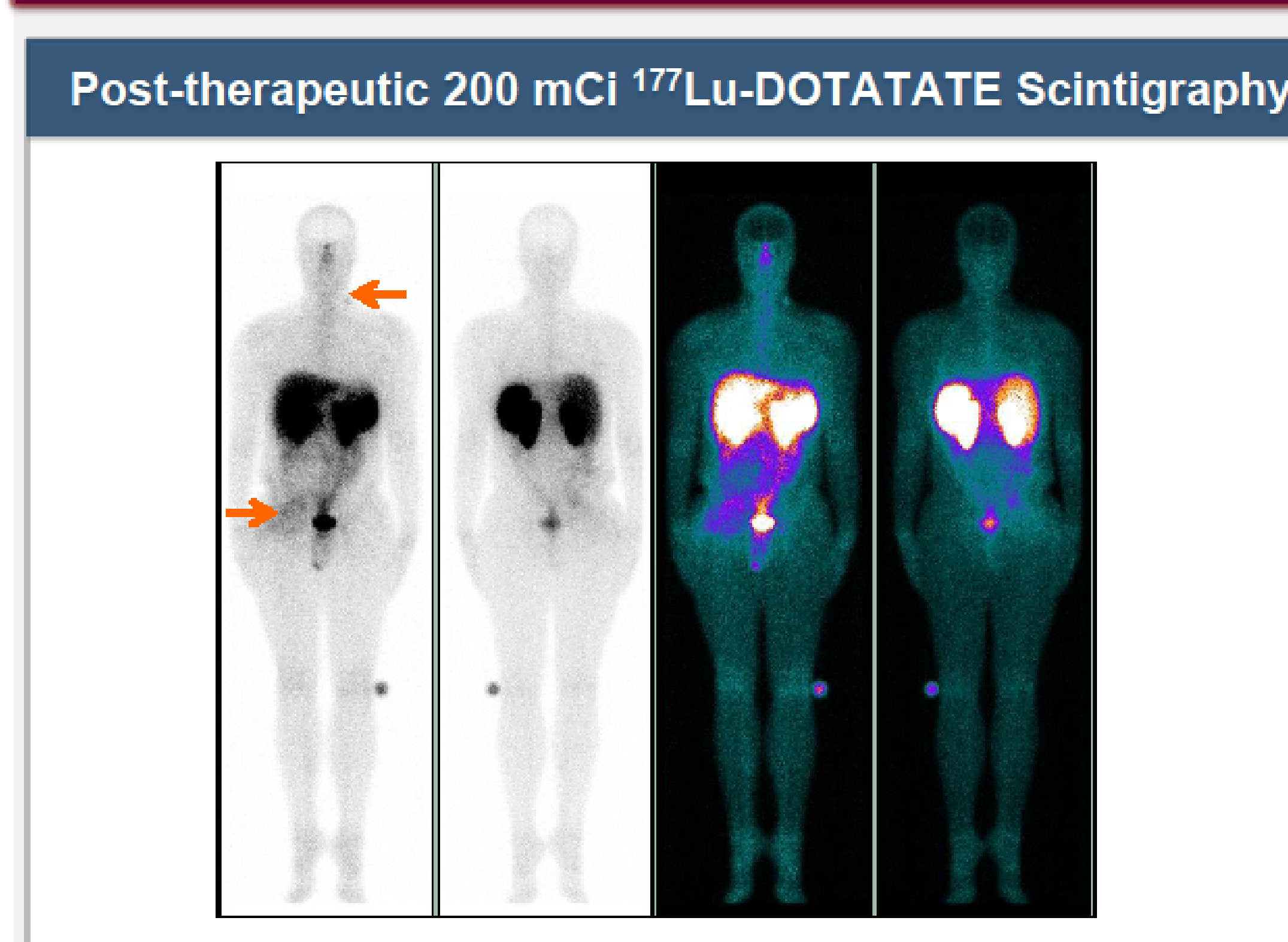

Low uptake: withdrawal of ${ }^{177}$ Lu-DOTATATE treatment
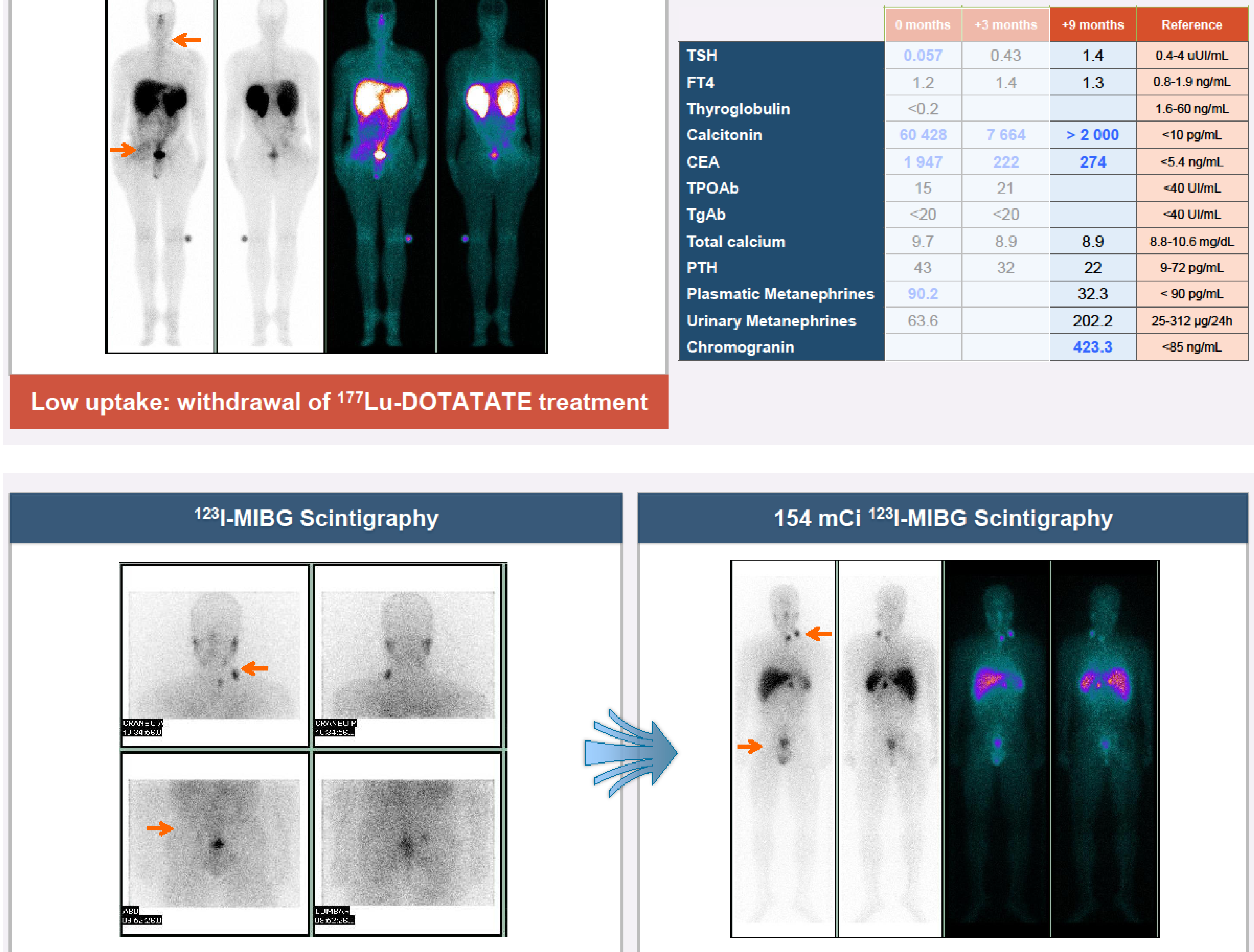

$154 \mathrm{mCi}{ }^{123}$-MIBG Scintigraphy

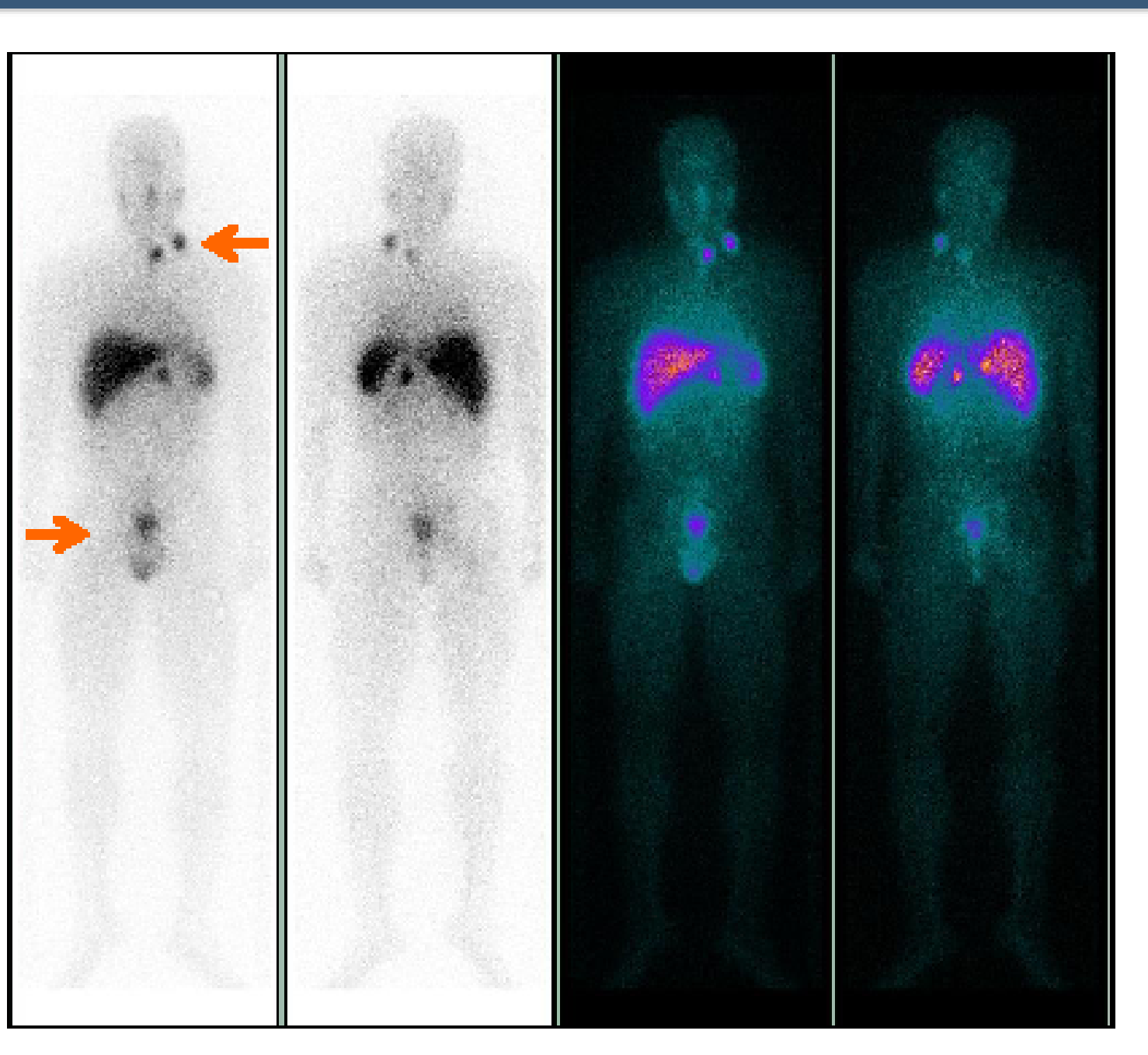

Moderate/High uptake: ongoing treatment

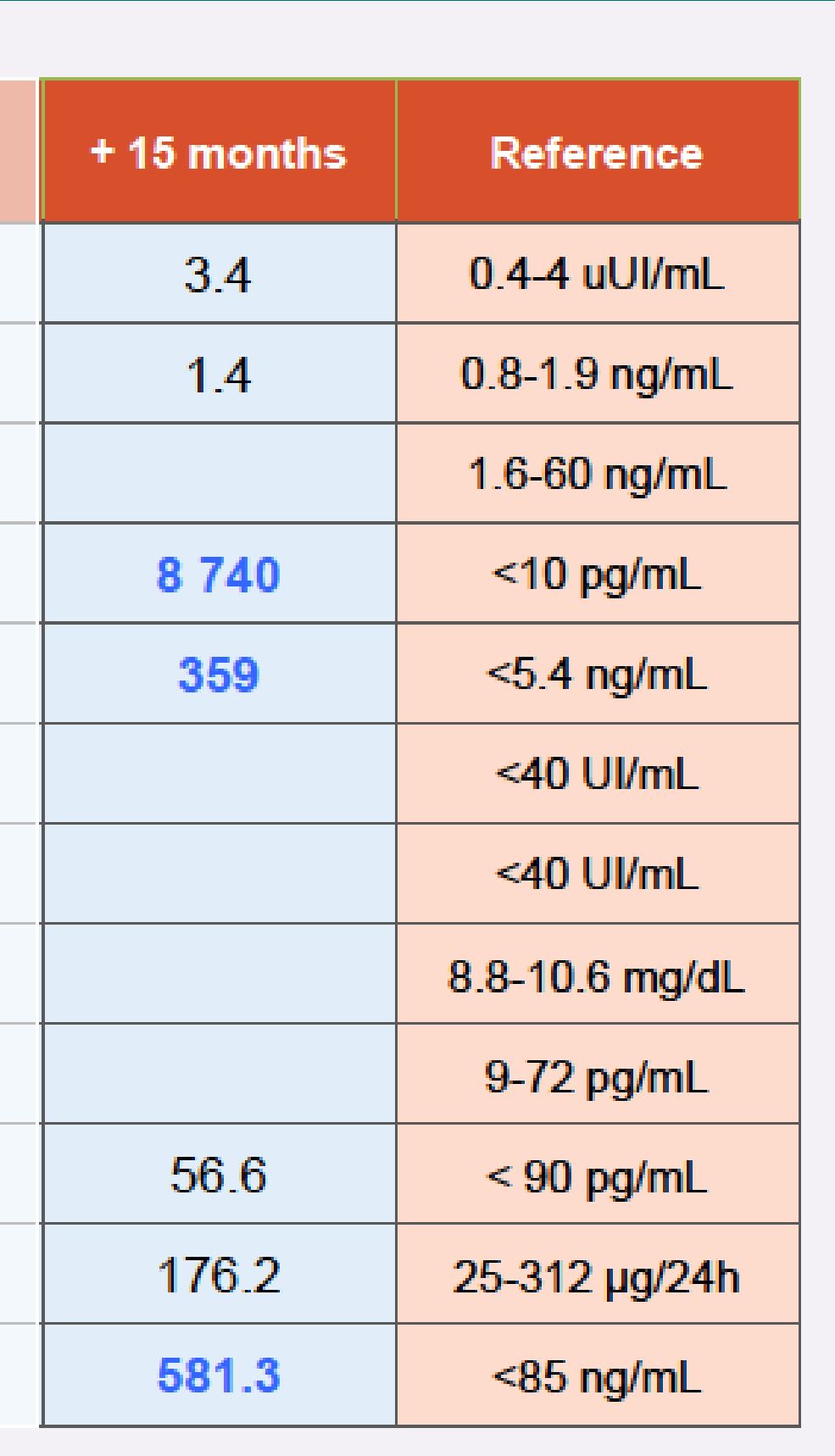

